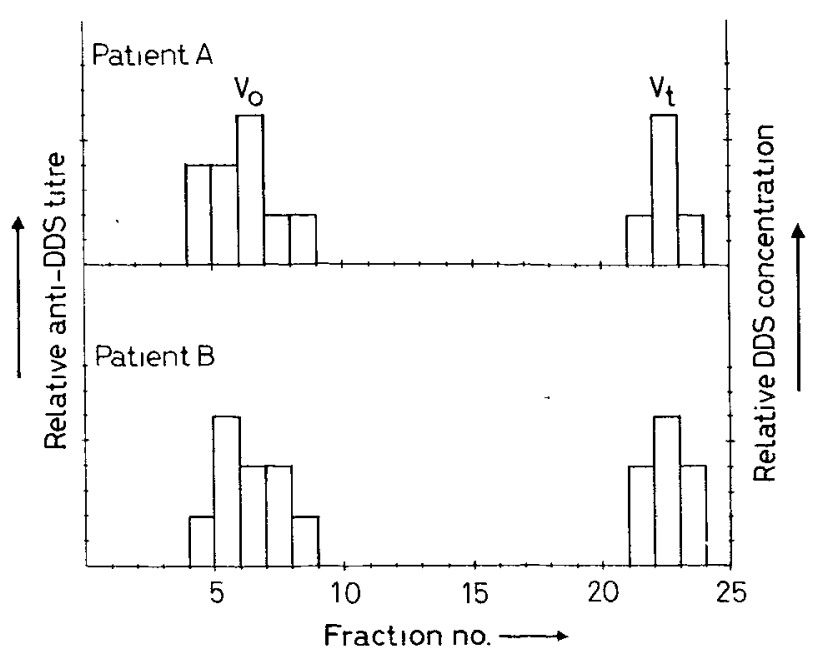

Gel chromatographic profile of dapsone (DDS) and anti-DDS antibody in dissociated CIC for sera of two lepromatous patients.

G-200 column $(1 \times 10 \mathrm{~cm}) ; V_{0}=$ void volume and $V_{t}=$ total volume of column. Relative titre for anti-DDS (by ELISA ${ }^{6,7}$ ) and DDS concentration (by ELISIT ${ }^{6,7}$ ).

have no evidence that such complexes play any role in ENL. Nevertheless, screening for antibody to dapsone and for CICs of dapsone/anti-dapsone could be important in longitudinal studies of the response of leprosy patients to chemotherapy.

We thank Mrs M. de Wit for her technical assistance.

w.H.O. International Immunology Traming and Research Centre,

Plesmanlaan 125 ,

P. K. DAS

Amsterdam, Netherlands

P. R. KLATSER

K. W. Pondman

Department of Tropical Hygiene,

H. HUIKESHOVEN Royal Tropical Institute,

Amsterdam

J. E. LANDHEER

D. L. LEIKER

Laboratory for Leprosy

and Mycobacterial Research,

National Institute for Medical Research,

London NW7

R. J.W. REES

\section{SECONDARY HYPERAMMONEMIA: A POSSIBLE MECHANISM FOR VALPROATE ENCEPHALOPATHY}

SIR,-Hyperglycinæmia, hyperglycinuria, ${ }^{1}$ propionicaciduria $^{2}{ }^{2}$ and Reye's syndrome ${ }^{3}$ have been reported in epileptic patients taking the anticonvulsant drug valproic acid (VPA). While investigating possible mechanisms of VPA toxicity we found increased plasma glycine and propionic acid concentrations in symptom-free patients taking VPA (table I). With informed consent, loading tests with $500 \mathrm{mg}$ VPA orally were done in three children who had experienced severe vomiting, lethargy, or coma while on VPA. Plasma propionate rose from baseline 5 to $82 \mathrm{nmol} / 1$ (case 1 ), 21 to $81 \mathrm{nmol} / 1$ (case 2), and 14 to $62 \mathrm{nmol} / 1$ (case 3 ) by $3 \mathrm{~h}$ after the dose. However, these data did not explain why some children became ill from VPA; these levels of glycine and propionate are not nearly as high

7. Huikeshoven $\mathrm{H}$, de Wit $M$, Soeters A, Eggelte TA, Landheer JE, Leiker DL. Leprosy Rev (in press).

8. Ridley DS, Jopling WH. Classification of leprosy according to immunity: a five group system. Int $\mathcal{J}$ Lepr 1966; 34: 255-73.

1. Jaeken J, Corbell L, Casaer P, Carchon H, Eggermont E, Eeckels R. Dipropylacetate (valoproate) and glycine metabolism. Lancet, 1977, ii: 617.

2. Schmid RD: Propınic acic and dipropylacetic acid in the urine of patients treated with dipropylacetic acid. Clin Chim Acta; 1977; 74: 39-42.

3. Gerber N, Dickinson RG, Harland RC, Lynn RK, Houghton D, Antonias JI, Schimschock JC. Reye-like syndrome associated with valproic acid therapy. F Pediat 1979; 95: 142-44.
TABLE I-GLYCINE AND PROPIONATE CONCENTRATIONS

\begin{tabular}{l|c|c}
\hline \multicolumn{1}{c|}{ Aminoacid } & Patients $(\mathrm{n}=26)$ & Controls $(\mathrm{n}=18)$ \\
\hline Glycine $(\mathrm{mmol} / \mathrm{l})$ & $374 \pm 75$ & $251 \pm 99$ \\
Propionate $(\mathrm{nmol} / \mathrm{l})$ & $33 \pm 20$ & $\star$ \\
\hline
\end{tabular}

*Normal range $1-3 \mathrm{nmol} / 1$.

as those found in children ill with inborn errors of metabolism involving these compounds. ${ }^{4,5}$

Recently, we observed hyperammonæmia in a patient taking VPA who became obtunded but had no evidence of liver disease or drug intoxication. Since hyperammonæmia occurs in several metabolic diseases, including propionyl CoA carboxylase deficiency, ${ }^{6}$ we investigated a possible relation between VPA, propionate, and ammonia that might suggest a mechanism of VPA toxicity.

A 4-year-old $15 \mathrm{~kg}$ girl taking phenytoin $125 \mathrm{mg}$, primidone $175 \mathrm{mg}$, acetazolamide $375 \mathrm{mg}$, trimethadione $1800 \mathrm{mg}$, and valproic acid $750 \mathrm{mg}$ daily became lethargic with vomiting and fever and progressive obtundation. Anticonvulsant levels, electrolytes, liver and renal function tests, coagulation studies, blood gases, cell counts, lactic acid, and CSF studies were normal. Ammonia was $80 \mu \mathrm{mol} / 1$ (control 28, normal 11-35) and remained high for 4 days. VPA was discontinued on admission, By day 5 she was alert, and ammonia was $36 \mu \mathrm{mol} / 1$ (control 30). With informed consent a $500 \mathrm{mg}$ VPA load test was done on day 7 (table II). Glycine was determined on a Beckman 119

TABLE II-VPA LOADING TEST RESULTS

\begin{tabular}{l|c|c|c|c|c}
\hline \multicolumn{1}{c|}{} & $0 \min$ & 60 & 120 & 180 & 240 \\
\hline VPA $(\mu \mathrm{g} / \mathrm{ml})$ & $2 \cdot 2$ & 75.4 & 64.4 & 51.9 & $12 \cdot 1$ \\
Propionate $(\mathrm{nmol} / \mathrm{l})$ & 0.0 & 265 & 60 & 65 & $\star$ \\
Ammonia $(\mu \mathrm{mol} / \mathrm{l})$ & 30 & 44 & 32 & 42 & 34 \\
Glycine $(\mathrm{mmol} / \mathrm{l})$ & 201 & 257 & 237 & $\ldots$ & $\cdots$ \\
\hline
\end{tabular}

*Hæmolysed.

CL amino-acid analyser, VPA and propionate were measured by gas liquid chromatography, and ammonia by the glutamate dehydrogenase method. $1 \mathrm{~h}$ after the loading dose, VPA, propionate, and ammonia levels had increased significantly and the child became lethargic. As the levels returned to normal at the end of the test, she again became alert.

Propionyl CoA inhibits carbamyl phosphate synthetase I (CPS-I) activity in vitro ${ }^{7}$ so that blood ammonia may be increased in patients with propionyl CoA carboxylase deficiency with raised propionate levels. ${ }^{8}$ A decreased activity of CPS-I has been reported in such patients. ${ }^{9}$ VPA apparently does not inhibit propionyl CoA carboxylase activity, ${ }^{10}$ but metabolic conversion of VPA to propionate and related compounds could explain the increased propionate levels in patients taking VPA. This increase in blood propionate may then inhibit CPS-I, resulting in accumulation of ammonia in the blood and a secondary ammonia encephalopathy. Since propionate may

4. Ando $T$, Rasmussen K, Nyhan WL, Donnel GN, Barnes ND. Propionic acidemia in patients with ketotic hyperglycinemia. F Pediat 1971; 78: $827-32$.

5. Frazier DM, Summer GK, Chamberlin HR. Hyperglycinuria and hyperglycinemia in two siblings with mild developmental delays. Am $\mathcal{F}$ Dis Child 1978; 132: 777-81.

6. Shafai T, Sweetman L, Wegler W, Goodman SI, Fennessey PV, Nyhan WL. Propionic acidemia with severe hyperammonemia and defective glycine metabolism. FPediat 1978; 92: 84-86.

7. Gruskay JA, Rosenberg LE. Inhibition of hepatic mitochondrial carbamyl phosphate synthetase (CPS-I) by acyl CoA esters. Pediat Res 1979; 13 475 .

8. Wolf B, Hsia YE, Tanaka K, Rosenberg LE, Correlations between serum propionate and blood ammonia concentrations in propionic acidemia. $\mathcal{F}$ Pediat 1978; 93: 471-73.

9. Harris DJ, Yang BIY, Wolf B, Snodgrass PJ. Dysautonomia in an infant with secondary hyperammonemia due to propionyl $\mathrm{CoA}$ carboxylase deficiency. Pediatrics 1980; 65: 107-10.

10. Wolf B. Dipropylacetate and propionyl CoA carboxylase. Lancet; ij: 369 
also interfere with mitochondrial glycine transport ${ }^{11}$ this may account for the hyperglycinæmia seen in patients taking VPA. It has been suggested that $\mathrm{N}$-acetyl glutamate synthetase is inhibited by increased propionyl CoA concentrations. ${ }^{6}$ Since $\mathrm{N}$-acetyl glutamate activates CPS-I, inhibited formation of this compound could also reduce the activity of CPS-I.

It seems that secondary hyperammonæmia, not due to liver disease, may occur in patients taking VPA, and this may explain why some patients become stuporous or comatose while taking this drug. ${ }^{12}$ Blood ammonia levels should be monitored in such patients. The mechanism of ammonia encephalopathy may be different from that of the hyperammonæmia seen in patients with hepatitis due to VPA. ${ }^{3,13}$

This child was on several drugs, and a single load test may not compare with chronic use. Further studies of ammonia metabolism in patients taking VPA should help clarify the mechanism of VPA toxicity.

Departments of Pediatrics and Neurology, University of Michigan Medical Center,

David L. Coúlter Ann Arbor, Michigan 48109, U.S.A

\section{THE IRISH GIANT: NEW OBSERVATIONS} CONCERNING THE NATURE OF HIS AILMENT

SIR,-Charles Byrne, the Irish giant who attracted considerable interest when he came to London in 1782 and whose skeleton is one of the main attractions of the Hunterian Museum, continues to yield up new findings almost two hundred years after his death in 1783 at the age of 22 years.

Sir Arthur Keith and Harvey Cushing ${ }^{14-16}$ showed by direct inspection of the pituitary fossa that Charles Byrne had a pituitary adenoma causing the extraordinary growth of his body. This was confirmed in 1963 by a skull radiograph which demonstrated enlargement of the sella turcica. ${ }^{17}$ Some new insights have now been provided by a reinspection of the skeleton, by a radiograph of its right hand kindly obtained by the curator of the museum, Miss Elizabeth Allen, by some measurements mentioned in the museum catalogue, ${ }^{18}$ and by other measurements obtained from a photograph provided by the Hunterian Museum.

On both wrists the distal epiphyseal lines of the radius are open. This is not mentioned in the published description of the skeleton, but is confirmed by the radiograph (see figure). John Hunter must have noted this because he used additional nails and wires to secure the radial epiphyses. Comparison with an atlas of skeletal development ${ }^{19}$ shows that Charles Byrne had a bone maturity of only 17 years. Skeletal maturation therefore was retarded. Measurements of the skeleton are compared with the normal values of a longitudinal growth study; ${ }^{20}$ the

11. Vgarte M, Lopez-Lahoya J, Garcia ML, Benavides J, Valdivieso F. Possible explanation for hyperglycinemia in propionic acidemia and methylmalonic acidemia. F Inher Metab Dis 1979; 2: 93-96.

12. Sackellaris JC, Lee SI, Dreifuss FE. Stupor following administration of valproic acid to patients receiving other anticonvulsant drugs. Epilepsio 1979; 20: 697-703.

13. Jacobi G, Thorbeck R, Ritz A, Jansen W, Schmidts HL. Fatal hepatotoxicity in child on phenobarbitone and sodium valproate. Lancet 1980; $712-13$

14. Cushing H. Neurohypophysical mechanisms from a clincal standpoint. Lancet 1930 ; ii: $119-27$

15. Fulton J. Harvey Cushing: a biography. Springfield, 7 Illinois: Charles C Thomas, 1946.

16. Keith A. An inquiry into the nature of the skeletal changes in acromegaly. Lancet 1911; i: 993-1002.

17. Bergland RM. New information concerning the Irish Giant. f Neurosurg $1965 ; 23: 265-69$.

18. Descriptive catalogue of the physiological series in the Hunterian Museum of the Royal College of Surgeons of England, London, 1971.

19. Greulich WW, Pyle SI. Radiographic atlas of skeletal development of the hand and wrist. Stanford: 1959.

20. Prader A, Issler C, Molinari L, Largo RH. Physical growth in Swiss children from 0 to 20 years of life. Helv Pcediat Acta 1980, suppl 45 (in press)

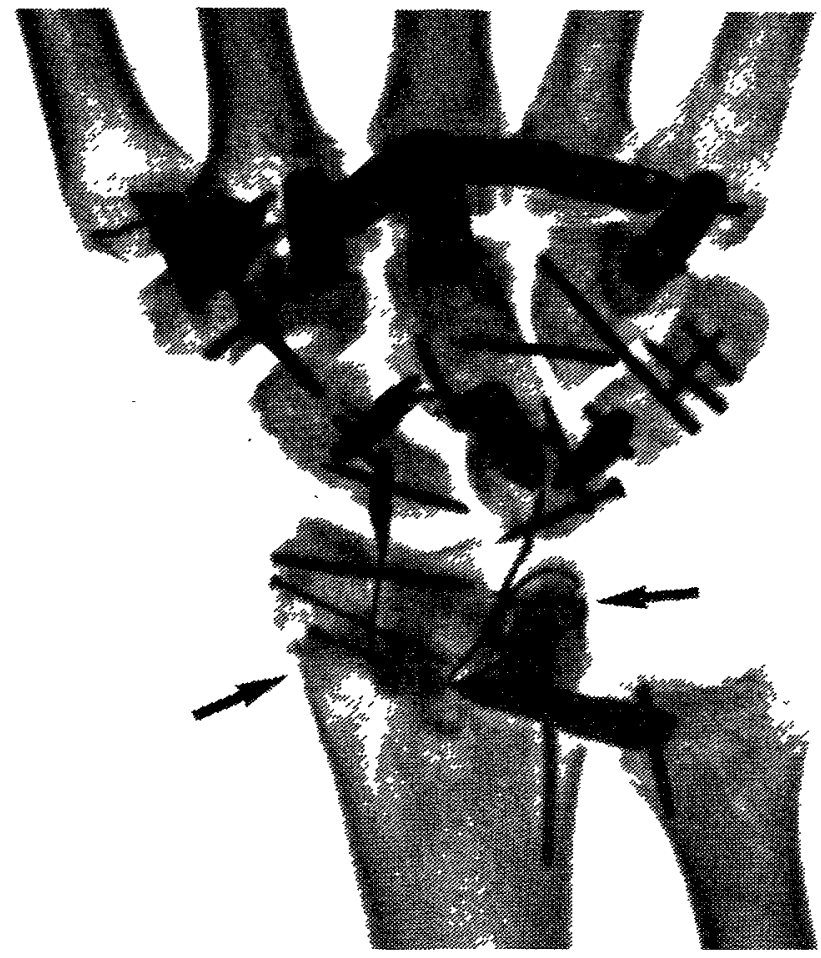

Radiograph of right wrist of Charels Byrne (O'Brien).

Arrows mark open epiphyseal cleft.

differences are expressed in standard deviation scores (SDS) (see table).

A comparison of the dimension of the skeleton with today's normal growth values may not be valid because of secular acceleration of growth over the past two centuries. However, comparison with contemporary data would result in even higher SDS values. The SDS value of the body height is extreme and excludes the possibility that Charles Byrne was just "a tall man". The relation of the height, sitting height, and subischial leg height demonstrates that the giantism was harmonic and not eunuchoidal. The measurements of the head, shoulder width, and pelvic diameter give relatively lower SD scores in comparison to the body height. This is the exact opposite to the anthropometric signs produced by growth hormone deficiency. ${ }^{21}$

These data confirm that Charles Byrne had suffered from a growth-hormone-producing adenoma. The tumour apparently did not affect the gonadrotrophin production during early adolescence since no eunuchoid proportions ensued. However,

21. Zachmann M, Fernandez F, Tassinari D, Thakker R, Prader A. Anthropo metric measurements in patients with growth hormone deficiency prior to treatment with human growth hormone. Eur f Pediat 1980; 133: 277-82.

ANTHROPOMETRIC MEASUREMENTS OBTAINED FROM THE SKELETON OF CHARLES BYRNE IN COMPARISON TO THE NORMAL VALUES OF A LONGITUDINAL GROWTH STUPY ${ }^{7}$

\begin{tabular}{l|c|c}
\hline \multicolumn{1}{c|}{} & $\begin{array}{c}\text { Measurement } \\
(\mathrm{m})\end{array}$ & SDS $^{\star}$ \\
\hline Standing height & 2.31 & +7.7 \\
Sitting height & 1.16 & +6.4 \\
$\begin{array}{l}\text { Standing subischial leg height } \\
\text { (standing height minus sitting height) }\end{array}$ & 1.15 & +6.7 \\
Bihumeral (shoulder) width & 0.52 & +5.5 \\
Biiliac (pelvis) width & 0.36 & +4.6 \\
Head circumference & 0.593 & +2.3 \\
Fronto-occipital diameter & 0.214 & +3.1 \\
\hline
\end{tabular}

$\star \operatorname{SDS}=(\mathrm{x}-\tilde{\mathrm{x}}) \div \mathrm{s}$, where $\mathrm{x}=$ measurement, $\tilde{\mathrm{x}}=$ normal mean of young adult Swiss males at age of 20 years, and $s=$ standard deviation at that age. 